\title{
Is Incarceration a Contributor to Health Disparities? Access to Care of Formerly Incarcerated Adults
}

\author{
Sonali P. Kulkarni $\cdot$ Susie Baldwin • \\ Amy S. Lightstone $\cdot$ Lillian Gelberg · \\ Allison L. Diamant
}

Published online: 3 February 2010

(C) The Author(s) 2010. This article is published with open access at Springerlink.com

\begin{abstract}
Despite the disproportionate prevalence of incarceration in communities of color, few studies have examined its contribution to health disparities. We examined whether a lifetime history of incarceration is associated with recent access to medical and dental care. We performed a secondary data analysis of the 2007 Los Angeles County Health Survey, a population-based random-digit-dialing telephone survey of county households. Any history of incarceration in a prison/jail/detention center as an adult was assessed for a random subsample. Bivariate and multivariate logistic regression analyses examined whether incarceration history was associated with access to care, controlling for other characteristics. Ten percent of our study population reported a history of incarceration. While persons with an incarceration history were similar to their peers with regard to health and insurance status, their access to medical and dental care
\end{abstract}

\section{S. P. Kulkarni $(\bowtie)$}

Robert Wood Johnson Clinical Scholars Program, University of California Los Angeles, 911 Broxton Avenue 3rd floor, Los Angeles, CA 90024, USA

e-mail: skulkarni@mednet.ucla.edu

S. Baldwin - A. S. Lightstone

Office of Health Assessment and Epidemiology, Los Angeles County Department of Public Health,

313 N. Figueroa St., Room 127, Los Angeles, CA 90012, USA

L. Gelberg

Department of Family and Community Medicine, University of California Los Angeles, BOX 957087, 10880 Wilshire Blvd, Ste 1800, Los Angeles, CA 90095-7087, USA

\section{A. L. Diamant}

Department of General Internal Medicine, University

of California Los Angeles, BOX 951736, 911 Broxton Plz,

Los Angeles, CA 90095-1736, USA was worse. Incarceration history was independently associated with disparities in access to care. Interventions to improve the health of communities affected by high rates of incarceration could include efforts that enable access to care for formerly incarcerated adults.

Keywords Incarceration - Health disparities .

Access to care $\cdot$ Communities of color

\section{Introduction}

The United States currently houses the world's largest prison population [1]. With more than 600,000 ex-offenders released from state and federal prisons annually and an estimated nine million from jails, formerly incarcerated persons comprise a part of every American community [2, 3]. Communities of color, however, are home to a disproportionate number of ex-offenders and bear the health burdens that previously incarcerated adults may bring to their communities such as a higher prevalence of risky health behaviors, multiple morbidities, poor health, and barriers to care [4].

Inmates in prisons and jails have been shown to have a higher burden of chronic diseases such as hypertension, diabetes, asthma, chronic liver disease, and HIV than the general population [5, 6]. However, access to medical care within detention centers and correctional institutions, particularly jails, remains poor [3, 7]. Furthermore, upon release from prison or jail, ex-offenders face interruptions in their medical care stemming from the limited availability of health care, a lack of health insurance, and lack of adequate discharge planning [8-12].

While much attention has been focused on the risk of communicable diseases associated with prisoner reentry, 
less is known about other health burdens borne by former prisoners, their families, and communities such as their health status and access to needed medical care [13-15]. Despite evidence suggesting that incarcerated persons are sicker and face disruptions in their care upon release, the contribution of incarceration to an individual's health status after he or she reenters the community has not been well studied.

As home to the largest population of former prisoners of any metropolitan area in the country, the issue of health and access to care among former prisoners holds great importance for Los Angeles County [2]. To describe the association between adult incarceration history and access to medical and dental care, and test whether incarceration history is an independent predictor of access to care after controlling for other characteristics, we utilized a population based health survey in Los Angeles County. We hypothesized that incarceration history is associated with decreased access to care among former prisoners and therefore may be perpetuating health disparities in communities of color.

\section{Methods}

\section{Study Population}

We performed a secondary data analysis of the 2007 Los Angeles County Health Survey (LACHS), a populationbased random-digit-dialing telephone survey of Los Angeles County residents, conducted from April 3, 2007 through January 22, 2008. The survey was conducted in 6 languages and served as a vehicle for tracking key health indicators and identifying emerging public health issues among County residents. The 2007 survey had a 40\% cooperation rate (\% of people who answered the telephone who were willing to complete the interview), and an $18 \%$ response rate (number of completed survey interviews divided by the total number of phone numbers selected). Of the 7200 non-institutionalized adults interviewed, a random subsample of 985 adults was asked about individual lifetime incarceration history. For the purposes of our analysis, we examined this subsample population, which did not differ significantly from the overall sample on any demographic characteristics.

\section{Study Variables}

\section{Independent Variable}

Our key independent variable was a history of any incarceration. In the LACHS, incarceration history was assessed with a single item: "Have you ever spent any time in a correctional facility, jail, prison, or detention center as an adult, that is, when you were age 18 years or older?" We classified persons as having a history of incarceration if they replied yes to this item. We excluded persons who did not know (1 person) or refused to answer the question (8 persons) for an analysis sample of 976.

\section{Explanatory Variables}

All measures were based on participants' self reports and were categorized using the Gelberg-Anderson Behavioral Model for Vulnerable Populations [16]. Predisposing Factors, characteristics that might predispose individuals to using medical care included, participants' age, gender, race, marital status, highest level of education, disability status, and employment status. Due to the limited size of the sample, we divided race into two categories based on available race/ethnicity data on incarceration rates in California, with African Americans and Latinos in one category and Whites, Asian Pacific Islanders, and American Indians in another [17]. Persons were categorized as married if they reported being married, domestic partners, or living together but not married. Education was divided into two categories: those having completed some high school or all of high school and those having completed any higher education (i.e., trade school, some college, all of college, or post graduate education). Participants were classified as disabled if they responded "yes" to any of the following three questions: "Are you limited in any way in any activities because of a physical, mental, or emotional problem for at least 3 months?", "Do you now have any health problems that require you to use special equipment, such as a cane, wheelchair, special bed, or special telephone?" and "Do you consider yourself a person with a disability?" Employment status was split into three categories: employed, including full or part time, unemployed and looking for work, and not in the workforce, which included retired and disabled and unable to work.

Enabling Factors for accessing care were measured by income, health insurance status, and perceived difficulty accessing care. Income was defined by percentage of the Federal Poverty Level (FPL). To determine which participants had continuous health insurance coverage in the preceding year versus those with discontinuous or no insurance in the past year, we calculated the number of individuals who were currently uninsured or had a period of being uninsured during the previous 12 months. We measured participants' perceived barriers to medical care using self-reports of difficulty accessing medical care (measured on a four-point Likert scale, ranging from very difficult, somewhat difficult, somewhat easy, to very easy).

Need for services (i.e health status) was captured using the question "In general, would you say your health was 
excellent, very good, good, fair, or poor?"[18] An index of chronic diseases included a prior diagnosis by a health professional of diabetes, heart disease, depression, hypertension, or high cholesterol. This was used to calculate the number of participants with two or more chronic diseases. We used information about previous diagnoses of diabetes, hypertension, and hypercholesterolemia as well as current smoking history, physical activity level, and BMI to calculate whether participants had greater than or equal to two cardiovascular risk factors [19].

\section{Outcome Variables}

Access to care was assessed using participants' recent health care utilization. Participants were asked whether they had a regular source of care, the duration of time since their last routine check-up with a doctor, and the duration of time since their last dental visit. Participants were asked whether, because of cost, they had been unable in the past year to see a doctor for a health problem or a dentist for any reason.

\section{Statistical Analysis}

To account for different probabilities of selection and response rates among demographic groups in the survey and subsample, we applied population weights to the data to reflect the Los Angeles County adult population. We used chi-square tests to assess the bivariate association of history of incarceration with predisposing, enabling, need, and access variables.

We used multivariate regression models to estimate the independent association of incarceration history with our access variables. To obtain adjusted odds ratios, we controlled for basic demographic factors (age, gender, race, income, and education) and other factors that differed by incarceration history group in the bivariates at the $P \leq 0.10$ level (employment status, disability, continuous insurance, and depression). For all analyses, we used SAS version 9.2 (SAS Institute Inc, Cary, NC).

\section{Results}

Predisposing, Enabling, and Need Characteristics

Among the 976 persons included in our study population, $10 \%$ reported a history of incarceration. Men had a much higher rate of prior incarceration than women $(P<0.001)$ (Table 1). The racial/ethnic distribution between the two groups was not statistically different $(P=0.13)$ but twelve percent of African American or Latinos reported a history of incarceration compared to nine percent of Whites or
Others. Compared to their peers, persons previously incarcerated were of similar age, marital status, and income, but were more likely to have a high school education or less $(P=0.06)$, more likely to be employed $(P=0.07)$, and more likely to report being disabled $(P=0.01)$.

Persons with a history of incarceration were as likely as those without a history of incarceration to have health insurance currently $(P=0.11)$ and to have had continuous health insurance coverage during the preceding year $(P=0.10)$. Formerly incarcerated individuals were not more likely to report difficulty accessing medical care $(P=0.33)$ and there was no significant difference in selfreported general health status $(P=0.38)$. They did, however, have a higher prevalence of diagnosed depression $(P=0.06)$. The formerly incarcerated and those without a history of incarceration had similar rates of two or more cardiovascular risk factors $(P=0.46)$ and two or more diagnosed chronic diseases $(P=0.17)$.

\section{Access to Medical and Dental Care}

Compared to those without a history of incarceration, the formerly incarcerated were significantly less likely to have a regular source of medical care (73.3 vs. $82.1 \%$, $P=0.03$ ), less likely to have visited a doctor for a routine check-up in the past year (46.4 vs. $59.8 \%, P=0.01$ ), and more likely to have not had visited a doctor for a routine check up in more than 5 years $(14.0$ vs. $6.8 \%, P=0.01)$ (Table 2). However, once we adjusted for covariates, the associations between incarceration history and regular source of care and incarceration history and routine doctor visits were explained by the covariates in the model.

Persons with an incarceration history were less likely to have seen a dentist for any reason in the past year (49.2 vs. $66.2 \%, P<0.001)$ and more likely to have received no dental care in over 5 years (19.4 vs. $10.3 \%, P=0.006)$. After adjustment, incarceration history was still significantly associated with being less likely to have received dental care in the past year and being more likely to have forgone dental care for more than 5 years.

Formerly incarcerated persons were about three times as likely to report being unable to see a doctor for a health problem $(22.5$ vs. $9.0 \%, P<0.001)$ or to see a dentist for any reason $(40.8$ vs. $17.7 \%, P<0.001)$ during the past year because of cost. Incarceration history remained a significant independent predictor of these unmet medical and dental needs even after adjustment for covariates.

\section{Discussion}

Rising rates of incarceration disproportionately affect African American and Latino communities with the 
Table 1 Characteristics of adults by incarceration history

\begin{tabular}{|c|c|c|c|}
\hline & \multicolumn{2}{|c|}{ Incarceration history } & \multirow[t]{2}{*}{$P$} \\
\hline & $\begin{array}{l}\text { Yes } \\
(n=102) \\
\%\end{array}$ & $\begin{array}{l}\text { No } \\
(n=874) \\
\quad \%\end{array}$ & \\
\hline \multicolumn{4}{|l|}{ Predisposing factors } \\
\hline Gender & & & $<0.001$ \\
\hline Male & 83.0 & 44.5 & \\
\hline Female & $17.0^{\mathrm{a}}$ & 55.5 & \\
\hline \multicolumn{4}{|l|}{ Age, years } \\
\hline $18-49$ & 65.8 & 65.1 & 0.89 \\
\hline$\geq 50$ & 34.2 & 34.9 & \\
\hline Race/ethnicity & & & 0.13 \\
\hline African American or Latino & 59.2 & 51.4 & \\
\hline White or other & 40.8 & 48.6 & \\
\hline Educational level & & & 0.06 \\
\hline $\begin{array}{l}\text { Less than high school/high } \\
\text { school }\end{array}$ & 49.5 & 39.9 & \\
\hline $\begin{array}{l}\text { Some college/college/post } \\
\text { graduate }\end{array}$ & 50.5 & 60.1 & \\
\hline Employed & 74.5 & 63.1 & 0.07 \\
\hline Married & 50.4 & 55.9 & 0.29 \\
\hline Disabled & 27.4 & 17.6 & 0.01 \\
\hline \multicolumn{4}{|l|}{ Enabling factors } \\
\hline \multicolumn{4}{|l|}{ Household income } \\
\hline 0-199\% FPL & 35.3 & 43.3 & 0.11 \\
\hline$\geq 200 \mathrm{FPL}$ & 64.7 & 56.7 & \\
\hline Current health insurance & 87.8 & 81.5 & 0.11 \\
\hline $\begin{array}{l}\text { Continuous health insurance in } \\
\text { past year }\end{array}$ & 68.1 & 75.6 & 0.10 \\
\hline $\begin{array}{l}\text { Difficulty accessing medical care } \\
\text { when needed very/somewhat } \\
\text { difficult }\end{array}$ & 29.0 & 24.6 & 0.33 \\
\hline \multicolumn{4}{|l|}{ Need factors } \\
\hline \multicolumn{4}{|l|}{ General health status } \\
\hline Excellent/very good/good & 84.8 & 81.3 & 0.38 \\
\hline \multicolumn{4}{|l|}{ Chronic disease } \\
\hline Depression & 18.2 & 11.7 & 0.06 \\
\hline $\begin{array}{l}\text { Two or more cardiovascular } \\
\text { risk factors }\end{array}$ & 41.1 & 37.4 & 0.46 \\
\hline Two or more chronic diseases & 27.5 & 21.6 & 0.17 \\
\hline
\end{tabular}

${ }^{a}$ Statistically unstable estimate, with variance $>23 \%$

lifetime chance of incarceration for an African American man being 1 in 3 and for a Latino man 1 in 6, compared to a 1 in 17 chance for a white man [20]. As home to a disproportionate number of previously incarcerated adults, communities of color bear the social and economic costs of any health burdens that returning prisoners bring to their communities. While earlier reports have examined ex-offenders during the pre-release and re-entry periods, our study adds to the literature by analyzing a population based survey to assess recent access to care of a diverse population of formerly incarcerated individuals now residing in the community.

Even though we found that persons with an incarceration history were similar to their peers with regard to predisposing, enabling, and need factors, their access to medical and dental care was worse. Our most significant finding was that individuals with an incarceration history were much more likely to have experienced cost as a barrier to receiving needed medical and dental care, even after adjustment for economic factors such as income, employment, and health insurance status. One potential explanation for this difference is that formerly incarcerated persons may have a different perception of the affordability of health care. Given the life disruption they face compared to their peers, formerly incarcerated individuals may experience competing economic priorities, not captured in our study, that limit their health care utilization [9]. Previous studies have shown that among formerly incarcerated persons, access and health care utilization are improved by indirect or non-monetary resources such as the receipt of public benefits, social support, and corrections-based discharge planning $[8,11]$.

Our data suggest that formerly incarcerated adults are less likely to have a regular source of care or to receive routine medical care. However, because the associations between incarceration history and regular source of care and time since last routine doctor check-up diminished after adjusting for covariates, our analyses raise the question of which other factors contributed to narrowing this difference. We considered performing an intervening variable analysis but were limited by the small sample size. By decomposing the relative contribution of each variable to reducing our independent variable's effect on the outcome, we would have been able to identify which modifiable factors counteract the effect of incarceration as a way to inform policy. We suggest this potential approach to researchers in the future.

Access to dental care was strongly associated with incarceration history. Close to over fifty percent of our sample reported having had a dental visit in the past year, compared to $25 \%$ of African Americans and Latinos and $47 \%$ of whites, nationwide [21]. While our Los Angeles County population fares better than the national population in terms of access to dental care, adults with an incarceration history were significantly less likely to receive timely or any dental care. Similarly high rates of unmet need for dental care have been documented previously for incarcerated adults [22]. The importance of access to dental care stems not only from the association between oral health and overall health, but may have particular importance for formerly incarcerated adults because poor dental health and tooth loss may serve as obstacles to obtaining employment [23, 24]. 
Table 2 Access to care of adults by incarceration history

\begin{tabular}{|c|c|c|c|c|}
\hline & \multicolumn{2}{|c|}{ Incarceration history } & \multirow[t]{2}{*}{ Unadjusted $\mathrm{OR}^{\mathrm{b}}$} & \multirow[t]{2}{*}{ Adjusted OR } \\
\hline & $\begin{array}{l}\text { Yes } \\
(n=102) \%\end{array}$ & $\begin{array}{l}\text { No } \\
(n=874) \%\end{array}$ & & \\
\hline \multicolumn{5}{|l|}{ Medical care } \\
\hline Regular source of care & 73.3 & 82.1 & $\begin{array}{l}0.60^{*} \\
(0.38,0.95)\end{array}$ & $\begin{array}{l}0.83 \\
(0.47,1.47)\end{array}$ \\
\hline \multicolumn{5}{|l|}{ Last routine check up with MD } \\
\hline Within 1 year & 46.4 & 59.8 & $\begin{array}{l}0.58^{*} \\
(0.39,0.87)\end{array}$ & $\begin{array}{l}0.76 \\
(0.48,1.21)\end{array}$ \\
\hline None within 5 years & $14.0^{\mathrm{a}}$ & 6.8 & $\begin{array}{l}2.24^{* *} \\
(1.22,4.12)\end{array}$ & $\begin{array}{l}1.36 \\
(0.64,2.87)\end{array}$ \\
\hline Unmet need to see MD for health problem & 22.5 & 9.0 & $\begin{array}{l}2.95^{* * *} \\
(1.77,4.93)\end{array}$ & $\begin{array}{l}4.05^{* * *} \\
(2.07,7.95)\end{array}$ \\
\hline \multicolumn{5}{|l|}{ Dental care } \\
\hline \multicolumn{5}{|l|}{ Last dental visit for any reason } \\
\hline Within 1 year & 49.2 & 66.2 & $\begin{array}{l}0.50^{\text {** }} \\
(0.33,074)\end{array}$ & $\begin{array}{l}0.56^{*} \\
(0.35,0.88)\end{array}$ \\
\hline None within 5 years & 19.4 & 10.3 & $\begin{array}{l}2.08^{* *} \\
(1.23,3.54)\end{array}$ & $\begin{array}{l}2.21^{*} \\
(1.18,4.14)\end{array}$ \\
\hline Unmet need to see dentist for any reason & 40.8 & 17.7 & $\begin{array}{l}3.20^{* * * *} \\
(2.10,4.90)\end{array}$ & $\begin{array}{l}3.83^{* * *} \\
(2.30,6.37)\end{array}$ \\
\hline
\end{tabular}

a Statistically unstable estimate, with variance $\geq 23 \%$

b Adjusted for incarceration history only

c Adjusted for incarceration history, age, gender, race, income, education, employment, disability, continuous insurance, and depression

* $P<0.05,{ }^{* *} P<0.01,{ }^{* * *} P<0.001$

The results of this study should be viewed in light of several limitations. Due to our cross-sectional design, we are limited in our ability to make causal inferences about the relationship between incarceration history and the outcome variables. Our analysis was also limited by the heterogeneity of the independent variable, incarceration history. Persons incarcerated at prisons, jails, and detention centers may meaningfully differ with regard to the impact their incarceration had on their lives. For example, someone who spent time in state prison for 10 years for a felony likely faces a very different set of obstacles to employment, social services, and health care than someone imprisoned in jail for 2 weeks for a misdemeanor or never found guilty of a crime. Place of incarceration, length of incarceration, length of time since incarceration, and type of criminal charges were unmeasured potential effect modifiers in our analysis. The variation in the magnitude of measure of the effect of incarceration on access to care likely varies across these measures but we could not capture this. If anything, this would bias our results toward the null. Future analyses would benefit from the development of better measurement tools to classify incarceration history for use in health services research. Another study limitation is the LACHS's low response rate, which has become a problem for all telephone surveys in recent years. In Los Angeles County, as in other urban areas with large transient and immigrant populations, telephone surveys are particularly difficult to execute. However, the survey research literature increasingly reveals that response rates are not the only, or even the best, measure of a survey's validity [25, 26]. With respect to sample composition, the population that responded to the 2007 survey was closely aligned with Los Angeles County's population estimates for 2006 in its distribution of age, gender, race/ethnicity and household income [27]. The prevalence of lifetime history of incarceration in our population sample $(10 \%)$, which was composed primarily of men, was similar to national prevalence estimates for men (11\%) [20].

\section{Conclusions}

The number of Americans who have served time in a correctional facility has increased dramatically over the 
past three decades but little is known about the effect of incarceration on the health and healthcare of these individuals. The 2007 LACHS offered a unique opportunity to examine the association between incarceration history and access to medical and dental care for formerly incarcerated persons living in Los Angeles County. Incarceration history was associated with disparities in access to medical and dental care and cost was a significant barrier to accessing needed care. Because incarceration affects African Americans and Latinos disproportionately, poor access for these individuals may be contributing to racial and ethnic health disparities. The field of health disparities research could advance the development of better measures of incarceration history and advocate for their inclusion in more population based studies. Interventions to improve the health of communities affected by high rates of incarceration could include efforts that enable access to care for formerly incarcerated adults.

\section{IRB Approval}

The use of data information from the Los Angeles County Health Survey was reviewed by the institutional review board of the University of California Los Angeles and the Los Angeles County Department of Public Health and was found to be exempt.

Acknowledgments Sonali Kulkarni was supported by the Robert Wood Johnson Foundation Clinical Scholars Program. There are no conflicts of interest to disclose.

Open Access This article is distributed under the terms of the Creative Commons Attribution Noncommercial License which permits any noncommercial use, distribution, and reproduction in any medium, provided the original author(s) and source are credited.

\section{References}

1. Hartney, C. (2006). Research from the national council on crime and delinquency: U.S. rates of incarcerations. Retrieved March 29, 2009, from http://www.nccd-crc.org/nccd/pubs/2006 nov_factsheet_incarceration.pdf.

2. Bureau of Justice Statistics, U.S. Department of Justice. (2004). Reentry trends in the U.S.: Releases from state prison. Retrieved February 14, 2009, from U.S. Bureau of Justice Statistics: http://www.ojp.usdoj.gov/bjs/reentry/releases.htm.

3. Beck, A. J. (2008). The importance of successful reentry to jail population growth. Retrieved March 5. 2009, from http://www. urban.org/projects/reentry-roundtable/upload/beck.ppt.

4. The Advancement Project. (2008). Prisoner rentry in Los Angeles: The who, what, and where of LA's parole and probation population. Retrieved September 12, 2008, from http://www. advanceproj.com.

5. Wilper, A. P., Woolhander, S., Boyd, J. W., Lasser, K. E., McCormick, D., Bor, D. H., et al. (2009). The health and health care of US Prisoners: Results of a nationwide survey. American Journal of Public Health, 99(4), 666-672.
6. National Commission on Correctional Health Care. (2002). The health status of soon-to-be-released inmates, Vol. 1. Retrieved September 10, 2008, from http://www.ncchc.org/pubs/pubs_ stbr.vol1.html.

7. Human Rights Watch. (2009). Detained and dismissed. Retrieved March 15, 2009, from http://www.hrw.org/en/reports/2009/03/16/ detained-and-dismissed.

8. Wang, E. A., White, M. C., Jamison, R., Goldenson, J., Estes, M., \& Tulsky, J. P. (2008). Discharge planning and continuity of health care: Findings from the San Francisco County jail. American Journal of Public Health, 98(12), 2182-2184.

9. Mallik-Kane, K. (2008). Illinois prisoners' reentry success three years after release. Retrieved September 20, 2008, from http://www.urban.org/publications/311214.html.

10. Hammett, T. M., Roberts, S., \& Kennedy, S. (2001). Health related issues in prisoner reentry to the community. Crime and Delinquency, 47(3), 390-409.

11. Lee, J., Vlahov, D., \& Freudenberg, N. (2006). Primary care and health insurance among women released from New York City jails. Journal of Health Care for the Poor and Underserved, 17(1), 200-217.

12. Tulsky, J. P., White, M. C., Dawson, C., Hoynes, T. M., Goldenson, J., \& Schecter, G. (1998). Screening for tuberculosis in jail and in clinic follow-up after release. American Journal of Public Health, 88(2), 223-226.

13. Thomas, J., \& Sampson, L. (2005). High rates of incarceration as a social force associated with community rates of sexually transmitted infection. Journal of Infectious Diseases, 191(3), S55-S60.

14. Hammett, T. M., Harmon, M. P., \& Rhodes, W. (2002). The burden of infectious disease among inmates of and releases from US correctional facilities, 1997. American Journal of Public Health, 92(11), 1789-1794.

15. Cohen, D., Scribner, R., Clark, J., \& Cory, D. (1992). The potential role of custody facilities in controlling sexually transmitted diseases. American Journal of Public Health, 82(4), $552-556$.

16. Gelberg, L., Andersen, R., \& Leake, B. D. (2000). The behavioral model for vulnerable populations: Application to medical care use and outcomes for homeless people. Health Services Research, 34(6), 1273-1302.

17. Bailey, A., Hayes J. (2007). Who's in Prison? The changing demographics of incarceration. Retrieved March 25, 2009, from http://www.ppic.org/main/publication.asp?i=701.

18. Ware, J. E., \& Sherbourne, C. D. (1992). The MOS 36 item short form health survey (SF-36). Conceptual framework and item selection. Medical Care, 30(6), 473-483.

19. Centers for Disease Control and Prevention. (2009). Heart disease risk factors. Retrieved March 25, 2009, from Centers of Disease Control and Prevention: http://www.cdc.gov/heartdisease/risk_ factors.htm.

20. Bureau of Justice Statistics, U.S. Department of Justice. (2004). Criminal offender statistics. Retrieved March 9, 2009, from U.S. Bureau of Justice Statistics: http://www.ojp.gov/bjs/crimoff.htm.

21. Gehshan, S. \& Lubin, T. (2007). Racial and ethnic disparities in oral health. Retrieved March 27, 2009 from http://www.ncsl. org/default.aspx?tabid=14452.

22. Clare, J. H. (1998). Survey, comparison, and analysis of caries, periodontal pocket depth, and urgent treatment needs in a sample of adult felon admissions, 1996. Journal of Correctional Health Care, 5(1), 89-101.

23. Desvarieux, M., Demmer, R. T., Rundek, T., Boden-Albala, B., Jacobs, D. R., Jr, Sacco, R. L., et al. (2005). Periodontal microdata and carotid intima-media thickness: The oral infections and vascular disease epidemiology study (INVEST). Circulation, 111(5), 576-582. 
24. Williams, N.H. (2009). Prison health and the health of the public: Ties that bind. Retrieved March 30, 2009, from http://www. communityvoices.org/Uploads/TiesThatBind_00108_00150.pdf.

25. Keeter, S., Kennedy, C., Dimock, M., Best, J., \& Craighill, P. (2006). Gauging the impact of growing nonrepsonse on estimates from a national RDD telephone survey. Public Opinion Quarterly, 70(5), 759-779.
26. Groves, R. M. (2006). Nonresponse rates and nonresponse bias in household surveys. Public Opinion Quarterly, 70(5), 646-675.

27. Walter R. McDonald \& Associates, Inc. (2006). Population and poverty estimates. Los Angeles, CA: Urban Research LA County CAO. 